OPEN ACCESS

Edited by:

Marta Concheiro-Guisan, John Jay College of Criminal Justice, United States

Reviewed by:

Svante Vikingsson,

Swedish National Board of Forensic

Medicine, Sweden

Jose Luiz Costa,

University of Campinas, Brazil

*Correspondence:

Helena Gaspar

hmgaspar@ciencias.ulisboa.pt

Alexandra M. M. Antunes alexandra.antunes@tecnico.ulisboa.pt

${ }^{\dagger}$ These authors have contributed equally to this work

Specialty section:

This article was submitted to Analytical Chemistry,

a section of the journal

Frontiers in Chemistry

Received: 22 September 2020 Accepted: 08 December 2020 Published: 12 January 2021

Citation:

Lopes BT, Caldeira MJ, Gaspar H and

Antunes AMM (2021) Metabolic Profile of Four Selected Cathinones in Microsome Incubations: Identification of Phase I and II Metabolites by Liquid

Chromatography High Resolution Mass Spectrometry.

Front. Chem. 8:609251.

doi: 10.3389/fchem.2020.609251

\section{Metabolic Profile of Four Selected Cathinones in Microsome Incubations: Identification of Phase I and II Metabolites by Liquid Chromatography High Resolution Mass Spectrometry}

\author{
Beatriz T. Lopes $^{1,2}$, Maria João Caldeira ${ }^{3}$, Helena Gaspar $^{2,4 * t}$ and \\ Alexandra M. M. Antunes ${ }^{1 * t}$
}

${ }^{1}$ Centro de Química Estrutural (CQE), Instituto Superior Técnico (IST), ULisboa, Lisboa, Portugal, ${ }^{2}$ BiolSI - Biosystems \& Integrative Sciences, Faculty of Sciences, University of Lisbon, Lisboa, Portugal, ${ }^{3}$ Laboratório de Polícia Científica da Polícia Judiciária (LPC/PJ), Novo edifício Sede da Polícia Judiciária, Lisboa, Portugal, ${ }^{4}$ MARE - Marine and Environmental Sciences Centre - Polytechnic of Leiria, Peniche, Portugal

Consumption of synthetic cathinones, the second largest class of new psychoactive substances (NPS) reported worldwide, represents a serious public health risk. One of the biggest challenges created by the rapid spread of NPS on the illegal drug market is the discovery of selective biomarkers for their detection in biological matrices, which is only possible through the study of their metabolic profile. The synthetic cathinones 4'-methyl- $N, N$-dimethylcathinone (4-MDMC), 4'-methyl- $N$, $N$-diethylcathinone (4-MDEC), 4'-chloro- $\alpha$-pyrrolidinovalerophenone (4CI-PVP), and 4'-chloroethylcathinone (4-CEC) are NPS recently seized in Europe, and, with the exception of 4-CEC, no metabolism study was reported for these cathinones. With the ultimate goal of overcoming this gap, these cathinones were incubated in vitro in human and rat liver microsomes in the presence of Phase I and II (glucuronidation) co-factors, using $\alpha$-pyrrolidinovalerophenone ( $\alpha$-PVP) as positive control. The metabolite identification was performed by liquid chromatography coupled to tandem high resolution mass spectrometry (LC-HRMS/MS). This allowed the identification of multiple Phase I and glucuronide metabolites of the selected cathinones. Additionally, a new glucuronide conjugate, derived from the recreational drug $\alpha$-PVP, was herein identified for the first time. Importantly, we have demonstrated that 4-MDMC and 4-MDEC can act as prodrugs of the controlled substances 4-MMC and 4-MEC, respectively. The metabolites herein identified are expected to play an important role not only by acting as potential selective biomarkers of the intake of the synthetic cathinones selected for this study but also to understand their potential adverse effects and link these causative agents to toxicities, thereby helping in the treatment of non-fatal intoxications.

Keywords: 4-CEC, 4CI-PVP, 4-MDEC, 4-MDMC, LC-HRMS, glucuronides, Phase I, metabolites 


\section{INTRODUCTION}

NPS are a range of substances, mostly synthetic, that have been emerging in the recreational drugs market with the purpose of mimicking the effects of classic drugs and circumvent legislation restrictions against illicit substances (German et al., 2014). The term NPS, according to the Directive (EU) 2017/2103 (EU, 2017) designates substances that are not covered by the Single Convention on Narcotic Drugs of 1961 neither by the Convention on Psychotropic Substances of 1971 but are likely to present health or social risks comparable to that posed by substances listed in those conventions. Despite the rapid spread of NPS over the last 10 years, the number of first detections of NPS, reported to the European Monitoring Center for Drugs and Drug Addiction (EMCDDA) through the European Union Early Warning System (EWS), has recently slowed-down, most likely due to changes in drug policies (EMCDDA and EUROPOL, 2019; EMCDDA, 2020) Nevertheless, the around 50 novel NPS that are still reported annually by EWS, together with the circulation in the market of about 400 previously reported NPS, pose serious health risks and constitute a great challenge for health and forensic institutions (EMCDDA, 2020). Importantly, until December 2019, a total of 790 NPS were monitored by EMCDDA (2017) overall, these represent more than three times the number of drugs currently controlled by international conventions.

Synthetic cathinones, the second largest group of NPS reported worldwide (UNODC, 2018; EMCDDA, 2020) are $\beta$ keto phenethylamines, structural analogs of cathinone, the major psychoactive alkaloid present in the leaves of Catha edulis. This plant, usually known as khat, is native from eastern Africa and southern Arabia, where it has been used, over centuries, due to its stimulant effects (Valente et al., 2014; Pieprzyca et al., 2020). In fact, synthetic cathinones are known to produce psychostimulant effects similar to methamphetamine, cocaine, or MDMA (ecstasy) by interacting with the plasma membrane transporters of the monoamine neurotransmitters, dopamine, norepinephrine, and serotonin, increasing their synaptic cleft concentration (German et al., 2014; Weinstein et al., 2017).

Synthetic cathinones were initially synthesized as an attempt to find new products with therapeutic applications due to their structural similarity with amphetamines (Kelly, 2011). Although some cathinones have been approved (FDA, 2020) and marketed as therapeutic agents, mainly as antidepressants or appetite suppressants (Arias et al., 2009; Kelly, 2011; Kang and Park, 2012; German et al., 2014; Onakpoya et al., 2016; FDA, 2020), most of them were banned or withdrawn from the market due

\footnotetext{
Abbreviations: 4-CEC, $\quad 4^{\prime}$-chloro- $N$-ethylcathinone; 4Cl-PVP, $\quad 4^{\prime}$-chloro$\alpha$-pyrrolidinovalerophenone; 4-CMC, $\quad 4^{\prime}$-chloro- $N$-methylcathinone; ESI+, electrospray ionization in the positive mode; HLM, human liver microsomes; LC- HRMS/MS, Liquid chromatography coupled to tandem high-resolution mass spectrometry; 4-MDEC, 4-methyl- $N, N$-diethylcathinone; 4-MDMC, 4methyl- $N, N$-dimethylcathinone; 4 -MEC, $4^{\prime}$-methyl- $N$-ethylcathinone; MS, mass spectrometry; 4-MMC, 4'-methyl- $N$-methylcathinone; MS/MS, tandem mass spectrometry; $m / z$, mass-to-charge ratio; NADPH, 5'-phosphate adenosine 2,5'-bisphosphate in its reduced form; NEH, $N$-ethylhexedrone; $\alpha$-PHP, $\alpha$ pyrrolidinohexanophenone; $\alpha$-PVP, $\alpha$-pyrrolidinopentiophenone; RLM, rat liver microsomes; QTOF, hybrid quadrupole time-of-flight; UDPGA, uridine diphosphate glucuronic acid.
}

to serious adverse effects or their potential misuse. Nonetheless, some cathinones are still in clinical use. One representative example is buproprion, which is an uncontrolled drug and is clinically used, mainly in the treatment of depression (Carroll et al., 2014; Costa et al., 2019; FDA, 2020).

The increase of acute intoxication and deaths associated with the consumption of cathinones (and other NPS) (Weinstein et al., 2017; Zaami et al., 2018) has resulted in their continuous inclusion in the International Drug Control Convention (UNODC, 2020), based on their risk assessment. Since 2015, 11 synthetic cathinones were included in the Schedule II of the Convention on Psychotropic Substances of 1971 (UNODC, 2020): mephedrone (4-MMC), methylenedioxypyrovalerone (MDPV), and methylone (in 2015); $\alpha$-pyrrolidinopentiophenone $\left(\alpha\right.$-PVP) (in 2016); $4^{\prime}$-methyl- $N$-ethylcathinone (4-MEC), pentedrone and ethylone (in 2017); ephylone (in 2019); $4^{\prime}-$ chloromethcathinone (4-CMC), $N$-ethylhexedrone (NEH), and $\alpha$-pyrrolidinohexanophenone ( $\alpha$-PHP) (in 2020).

Metabolic profiling of cathinones is crucial not only to understand potential adverse effects and link causative agents to toxicities but also to identify unique biomarkers of their intake, that will allow their unequivocal identification in biological matrices. Some cathinones undergo extensive metabolism in vivo (Uralets et al., 2014; Ellefsen et al., 2016), which is translated into low or even negligible urinary levels of the parent cathinone. Therefore, for these cases, the detection of cathinone's metabolites in biofluids, is the only possible way of proving the consumption of these NPS, in particular several hours after its intake. However, the metabolic profiles of most of the recently reported synthetic cathinones remain unknown. In fact, the large number of new substances that appear in the market makes it difficult for the authorities to respond with the needed analytical methodologies and metabolic studies for the identification and quantification of parent NPS and their metabolites in biofluids. In this regard, in vitro approaches, in particular liver microsome incubations, have proved their utility for studying the metabolic profile of cathinones (Meyer et al., 2010, 2012; Pedersen et al., 2013; Helfer et al., 2015; Negreira et al., 2015; Pozo et al., 2015).

With the ultimate goal of contributing for a proactive response in tackling the NPS problem, and within the scope of a protocol established between the Forensic Science Laboratory from Portuguese Criminal Police and the Lisbon University (Instituto Superior Técnico and Faculty of Sciences), the present work is aimed at determining the metabolite profile of four selected para-substituted cathinones: $4^{\prime}$-methyl- $\mathrm{N}, \mathrm{N}$-dimethylcathinone (4-MDMC), $\quad 4^{\prime}$-methyl- $N, N$-diethylcathinone (4-MDEC), $4^{\prime}$-chloro- $\alpha$-pyrrolidinovalerophenone (4Cl-PVP) and $4^{\prime}$-chloro- $N$-ethylcathinone (4-CEC) (Figure 1). The cathinone 4-MDMC is a structural isomer of the controlled drug 4MEC and pentedrone. 4-MDMC is structurally-related to amfepramone (DMC) and 4-MDEC is an isomeric structure of the recently scheduled drug NEH. Both these cathinones were seized for the first time during 2014 (EMCDDA, 2015) 4Cl-PVP and 4-CEC were reported in 2015 (EMCDDA, 2016) and 2016 (EMCDDA, 2017), respectively. Importantly, 4-MDEC was the most cytotoxic cathinone tested in HepG2 cells, in our previous work (Gaspar et al., 2018) and 4-MDMC was one of the five 
<smiles>O=C(c1ccc(Cl)cc1)C(CCPC(F)(F)Cl)N1CCCC1</smiles>
4CI-PVP<smiles>CCNC(C)C(=O)c1ccc(Cl)cc1</smiles>

4-CEC<smiles>CCN(CC)C(C)C(=O)c1ccc(C)cc1</smiles>

4-MDEC<smiles>Cc1ccc(C(=O)C(C)N(C)C)cc1</smiles>

4-MDMC<smiles>CCCC(C(=O)c1ccccc1)N1CCCC1</smiles>

$\alpha-P V P$

FIGURE 1 | Structures of the synthetic cathinones used in the current study.

most seized cathinones in EU, during 2016, while 4-CEC was the second one with highest overall quantities of seized products (EMCDDA, 2017). All the four selected cathinones are controlled in Portugal (Decree Law 15/93 and Decree Law 54/2013) and only 4-CEC has already been subject of metabolism studies (Fabregat-Safont et al., 2020; Wagmann et al., 2020).

\section{MATERIALS AND METHODS}

\section{Chemicals and Biochemicals}

The analytical standards of the hydrochloride salts of the selected cathinones (purity >97\%) used in this work were previously obtained and characterized within the scope of the protocol established between the Faculty of Sciences of the University of Lisbon (FCUL) and the Forensic Science Laboratory from Portuguese Criminal Police (LPC-PJ): 4-MDMC, 4-MDEC and $\boldsymbol{\alpha}$-PVP were synthesized at FCUL, as described by Gaspar et al. (2018), while 4CI-PVP and 4-CEC were obtained from seized samples provided by LPC-PJ (Antunes et al., 2020). Rat and human liver microsomes were obtained from Thermo Fisher Scientific-Gibco. All other commercially available reagents were acquired from Sigma-Aldrich Química, S.A. and used as received.

\section{Incubation of Cathinones With Human and Rat Liver Microsomes Generation of Phase I Metabolites}

Cathinones, at a concentration of $10 \mu \mathrm{M}(1 \mu \mathrm{L}, 5 \mathrm{mM}$ water solution), were incubated with human liver microsomes (HLM) and rat liver microsomes (RLM) (1 mg/mL), NADPH $(20 \mathrm{mM}$, $1 \mu \mathrm{L}$ ), for a total incubation volume of $200 \mu \mathrm{L}$ in $50 \mathrm{mM}$ ammonium bicarbonate buffer at $\mathrm{pH}$ 7.4. Each incubation was run in duplicate. Control incubations were conducted in the same conditions: (1) using water as a negative control, in the absence of cathinone; (2) in the absence of the NADPH cofactor; and (3) using heat-denatured $\left(90^{\circ} \mathrm{C}, 15 \mathrm{~min}\right)$ microsomes. Incubation of $\alpha$-PVP, was run at the same conditions, as a positive control incubation. The mixtures were incubated at $37^{\circ} \mathrm{C}$ and $100 \mu \mathrm{L}$ aliquot was collected following $2 \mathrm{~h}$ of incubation. Acetonitrile $(100 \mu \mathrm{L})$ was then added to quench the reactions. Following centrifugation at $10,000 \mathrm{~g}$ for $15 \mathrm{~min}$ at room temperature, the supernatants were collected and analyzed by liquid chromatography-tandem high resolution mass spectrometry (LC-HRMS/MS).

\section{Generation of Phase II Metabolites}

HLM and RLM (1 mg/mL) were preincubated for $15 \mathrm{~min}$, in ice, with alamethicin $\left(4 \mu \mathrm{L}, 5 \mathrm{mgmL}^{-1}\right)$ in $50 \mathrm{mM}$ ammonium

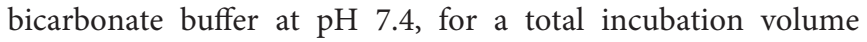
of $200 \mu \mathrm{L}$. Following the addition of $\mathrm{MgCl}_{2}(400 \mathrm{mM} ; 1 \mu \mathrm{L})$ and cathinone $(10 \mu \mathrm{M}$ final concentration; $1 \mu \mathrm{L}, 5 \mathrm{mM}$ water solution), the resulting solution was incubated for $5 \mathrm{~min}$ at $37^{\circ} \mathrm{C}$. NADPH $(20 \mathrm{mM}, 1 \mu \mathrm{L})$ and UDPGA $(250 \mathrm{mM}, 10 \mu \mathrm{L})$ were then added to start the Phase I and II reactions. Incubations were run in duplicate. Control incubations were conducted in the same conditions: (1) using water as a negative control, in the absence of cathinone; (2) in the absence of the NADPH and UDPGA cofactors; and (3) using heat-denatured $\left(90^{\circ} \mathrm{C}\right.$, $15 \mathrm{~min})$ microsomes. Incubation of $\boldsymbol{\alpha}$-PVP, was run at the same conditions, as a positive control incubation. The mixtures were incubated at $37^{\circ} \mathrm{C}$ and a $100 \mu \mathrm{L}$ aliquot was collected following $2 \mathrm{~h}$ of incubation. Acetonitrile $(100 \mu \mathrm{L})$ was then added to quench the reactions. Following centrifugation at $10,000 \mathrm{~g}$ for $15 \mathrm{~min}$ at room temperature, the supernatants were collected and analyzed by LC-HRMS/MS.

\section{Liquid Chromatography-Tandem High Resolution Mass Spectrometry (LC-HRMS/MS) Analyses}

LC-HRMS/MS analyses were performed on a Bruker Impact II quadrupole time-of-flight mass spectrometer equipped with an ESI source (Bruker Daltoniks, Bremen, Germany). Chromatographic separations were performed on: (1) an Ultimate 3000 RSLCnano system (ThermoFisher Scientific) using a Luna C18 column $(3.0 \mu \mathrm{m}, 2.0 \times 150 \mathrm{~mm}$; Phenomenex $)$ 
and an elution gradient of $0.1 \%$ formic acid in water (mobile phase A) and $0.1 \%$ formic acid in acetonitrile (mobile phase B) at a flow rate of $170 \mu \mathrm{L} / \mathrm{min}$. The elution conditions were as follows: $5-50 \% \mathrm{~B}$ for $6 \mathrm{~min}$; $50-100 \% \mathrm{~B}$ for $4 \mathrm{~min}$; isocratic elution with $100 \%$ B for $5 \mathrm{~min}$; $100-5 \%$ B for $4 \mathrm{~min}$; and finally, $5 \%$ B for $9 \mathrm{~min}$; or (2) an Ultimate 3000 RSLCnano system (ThermoFisher Scientific) using a HypersilGold C18 column $(2.1 \times 150 \mathrm{~mm}, 1.9 \mu \mathrm{m}$ particle size; ThermoFisher Scientific) at a flow rate of $200 \mu \mathrm{L} / \mathrm{min}$. The elution conditions were as follows: $5 \%$ B for $2.4 \mathrm{~min}$; $5-25 \%$ B for $2.1 \mathrm{~min}$; $25-70 \%$ B for $4.1 \mathrm{~min} ; 70-100 \%$ B for $3 \mathrm{~min}$; $100 \%$ B for $3 \mathrm{~min}$; $100-5 \%$ B for $2 \mathrm{~min}$; and finally $5 \% \mathrm{~B}$ for $6 \mathrm{~min}$. In either instance, the injection volume was $10 \mu \mathrm{L}$. The column and the autosampler were maintained at 40 and $8^{\circ} \mathrm{C}$, respectively. The mass spectrometric parameters were set as follows: end plate offset, $500 \mathrm{~V}$; capillary voltage, $4.5 \mathrm{kV}$; nebulizer, 40 psi; dry gas, $8 \mathrm{~L} / \mathrm{min}$; heater temperature, $200^{\circ} \mathrm{C}$. Spectra were acquired in the positive electrospray ionization mode ESI $(+)$. Internal calibration was performed for sodium formate cluster, with a sodium formate solution introduced to the ion source via a $20 \mu \mathrm{L}$ loop at the beginning of each analysis using a six-port valve. Calibration was then performed using high-precision calibration mode (HPC). Acquisition was performed in the $m / z 50-1,000$ range and in a data-dependent MS/MS mode with an isolation window of 0.5 , acquisition rate of $3 \mathrm{~Hz}$ and a fixed cycle time of $3 \mathrm{~s}$. Precursor ions were selected for auto MS/MS at an absolute threshold of 153 , with the active exclusion mode set at three spectra and released after $1 \mathrm{~min}$, but precursor ions with intensities in the range of $5 \mathrm{x}$ the previous intensities were reconsidered.

\section{Data Processing}

The acquired data were processed by DataAnalysis 4.1 software (Bruker Daltoniks). Extracted ion chromatograms (EIC), with a mass window of $\pm 5 \mathrm{ppm}$, were performed for searching the protonated molecule of the expected metabolites in the full scan spectra. Isotope cluster analysis was also used to identify chlorinated metabolites. All spectra corresponding to metabolites were then manually checked. The mass deviation from the accurate mass of the identified cathinone metabolites remained below $5 \mathrm{ppm}$ for the precursor and below $10 \mathrm{ppm}$ for product ions. The MS/MS spectra of the four selected cathiones and their identified metabolites are displayed in the Supplementary Material (Supplementary Figures 1-20).

\section{RESULTS AND DISCUSSION}

Taking into consideration that liver microsome incubations were already successfully used for the generation of metabolites that occur in vivo for other cathinones (Meyer and Maurer, 2010; Meyer et al., 2010, 2012; Strano-Rossi et al., 2010; Negreira et al., 2015), this in vitro model was used for the identification of the metabolite profile of the four para-substituted cathinones, 4-MDMC, 4-MDEC, 4Cl-PVP, and 4-CEC, selected for this study. HLM and RLM incubations were run for each of these cathinones. This decision was made based on our previous work (Godinho et al., 2018), where considerably more metabolites were identified in the incubations of the anti-HIV drug etravirine run in the rat liver S9 fraction when compared with the corresponding human liver S9 fraction incubations, due possibly to the higher enzymatic activity of the rodent fraction. Nonetheless, importantly, metabolites that were solely identified in vitro in the rat liver S9 incubations were also identified in vivo in the urine of HIV patients in etravirine therapy. Therefore, the fact that a specific metabolite is only detected in RLM does not necessarily mean that this metabolite cannot be formed in vivo in humans. However, in the current study, with very few exceptions, which will be conveniently mentioned, the metabolites were consistently identified in HLM and RLM incubations. This is particularly relevant since most in vivo toxicological studies are performed in rodent models (Prosser and Nelson, 2012).

For the identification of Phase I metabolites, incubations were run in the presence of NADPH co-factor. Glucuronidation of Phase I metabolites, and urinary excretion of the glucuronide conjugates represent the primary routes of cathinones biotransformation and elimination in humans (Ellefsen et al., 2016). Therefore, toward the identification of glucuronic acid conjugates of the selected cathinones, additional incubations were run in the presence of Phase I and II cofactors, NADPH and UDPGA, respectively, using both HLM and RLM that were preincubated with the pore-forming peptide alamethicin. This procedure was already proved to increase considerably the rates of the Phase II glucuronidation, while not effecting the Phase I capacity (Fisher et al., 2000). Since the metabolite profile of the drug $\alpha$-PVP was already determined in vivo (Shima et al., 2014) and in vitro (Negreira et al., 2015), $\boldsymbol{\alpha}$-PVP incubations were run in parallel with the incubations of selected cathinones, as positive controls.

LC-HRMS/MS, using hybrid quadrupole time-of-flight (QTOF) analyzer, was the method of choice for establishing the metabolic profile of the selected cathinones, since it constitutes one of the most useful analytical platforms for the identification of unknown metabolites. In fact, this methodology allows the direct and simultaneous detection of both Phase I and II metabolites, providing information about accurate mass and isotopic pattern not only of intact (de)protonated molecules, but also of fragment ions, which is of particular usefulness for metabolite identification.

As stated above, $\boldsymbol{\alpha}$-PVP incubations were performed in this study as positive controls. The fragmentation pattern obtained for this cathinone (Table 1, Supplementary Figure 1) is in agreement with the one reported by Negreira et al. (2015). Likewise, all Phase I $\boldsymbol{\alpha}$-PVP metabolites identified in current study (Table 1, Figure 2, Supplementary Figures 2-5) were also identified by these authors in vitro, including the product of $\alpha$-PVP ketone reduction (M1 $\alpha$-PVP), which was the most abundant metabolite found in in vivo for this cathinone (Tyrkkö et al., 2013). This result attests the viability of the experimental conditions used in the current study for identifying the metabolites that are most likely to be found in vivo. Of note is the identification of the Phase II metabolite M4 $\alpha$-PVP $(\mathrm{m} / z$ 426.2118, $-0.9 \mathrm{ppm}, \mathrm{C}_{21} \mathrm{H}_{32} \mathrm{NO}_{8}$ ) that stems from glucuronic acid conjugation of $\mathbf{M} 2 \alpha$-PVP, a Phase I metabolite formed upon $\alpha$-PVP keto reduction and hydroxylation of the pyrrolidine ring (Figure 2). The base peak of the tandem mass spectrum of this 
TABLE 1 | Structures of the $\alpha$-PVP metabolites identified in HLM and RLM incubations by LC-HRMS/MS (ESI+) analysis.

\begin{tabular}{|c|c|c|c|c|c|c|c|c|}
\hline Compound & Structure & $\begin{array}{c}{[\mathrm{M}+\mathrm{H}]^{+}} \\
(m / z)\end{array}$ & $\begin{array}{l}\text { Elemental } \\
\text { composition }\end{array}$ & $\begin{array}{l}\text { Error } \\
\text { (ppm) }\end{array}$ & $\begin{array}{l}\text { Production } \\
\qquad(m / z)\end{array}$ & $\begin{array}{l}\text { Elemental } \\
\text { composition }\end{array}$ & $\begin{array}{l}\text { Error } \\
\text { (ppm) }\end{array}$ & Identification \\
\hline \multirow{5}{*}{$\alpha-P V P$} & \multirow{5}{*}{ 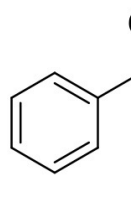 } & \multirow{5}{*}{232.1685} & \multirow{5}{*}{$\mathrm{C}_{15} \mathrm{H}_{22} \mathrm{NO}$} & \multirow{5}{*}{-4.7} & 161.0964 & $\mathrm{C}_{11} \mathrm{H}_{13} \mathrm{O}$ & +2.5 & \multirow{5}{*}{-} \\
\hline & & & & & 126.1281 & $\mathrm{C}_{8} \mathrm{H}_{16} \mathrm{~N}$ & +3.2 & \\
\hline & & & & & 105.0343 & $\mathrm{C}_{7} \mathrm{H}_{5} \mathrm{~N}$ & +7.6 & \\
\hline & & & & & 91.0541 & $\mathrm{C}_{7} \mathrm{H}_{7}$ & -1.9 & \\
\hline & & & & & 70.0650 & $\mathrm{C}_{4} \mathrm{H}_{8} \mathrm{~N}$ & -1.4 & \\
\hline
\end{tabular}
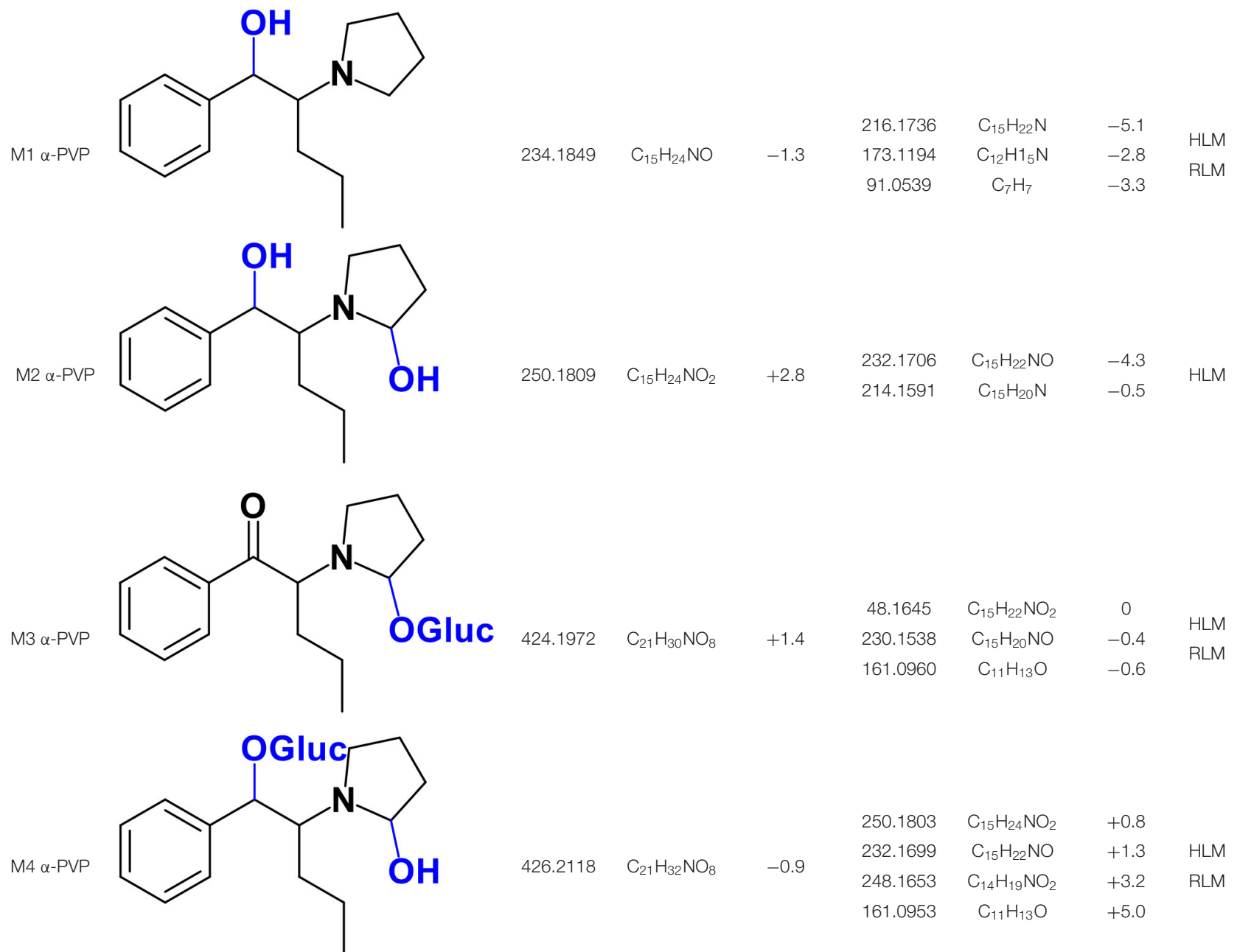

Also shown the corresponding experimental $\mathrm{m} / \mathrm{z}$ values and proposed elemental composition for the protonated molecule and characteristic fragment ions (presented with the associated error in ppm).

Phase II metabolite, at $m / z 250.1803\left(+0.8 \mathrm{ppm}, \mathrm{C}_{15} \mathrm{H}_{24} \mathrm{NO}_{2}\right)$ (Supplementary Figure 5), corresponds to the typical neutral loss of $176.0315 \mathrm{u}$ from the protonated molecule, corresponding to the glucuronide moiety. The occurrence of glucuronidation at the hydroxyl group resulting from the reduction of the keto group of the parent cathinone is suggested based on the observation of the product ion at $\mathrm{m} / z 161.0953\left(+5.0 \mathrm{ppm}, \mathrm{C}_{11} \mathrm{H}_{13} \mathrm{O}\right)$. In fact, the formation of this product ion can only be explained on basis of the loss of the hydroxylated pyrrolidine moiety from the fragment ion at $m / z 248.1653\left(+3.2 \mathrm{ppm}, \mathrm{C}_{14} \mathrm{H}_{19} \mathrm{NO}_{2}\right)$, which is proposed to be formed via the neutral loss of $178.0465 \mathrm{u}$ from the protonated molecule of M4 $\alpha$-PVP. Whereas, the in vivo occurrence of the parent Phase I metabolite was already evidenced by Tyrkkö et al. (2013) to the best of our knowledge, this constitutes the first report on the identification of the glucuronic acid conjugate of this $\alpha$-PVP Phase I metabolite. 


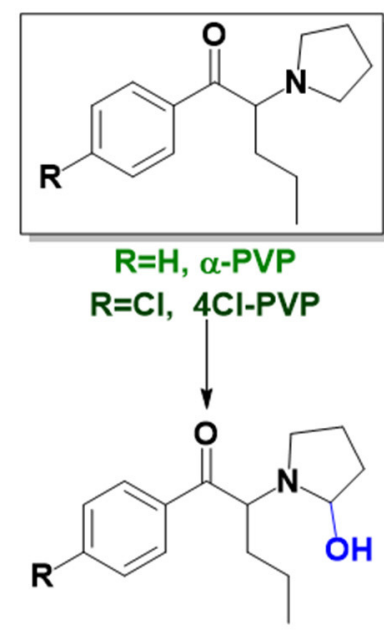

$\mathrm{R}=\mathrm{Cl}, \mathrm{M} 4$ 4CI-PVP<smiles>CCCC(C(=O)c1ccccc1)N1CCCC1OC</smiles>

$\mathrm{R}=\mathrm{H}, \mathrm{M} 3 \alpha-\mathrm{PVP}$

$\mathrm{R}=\mathrm{Cl}$, M5 4CI-PVP

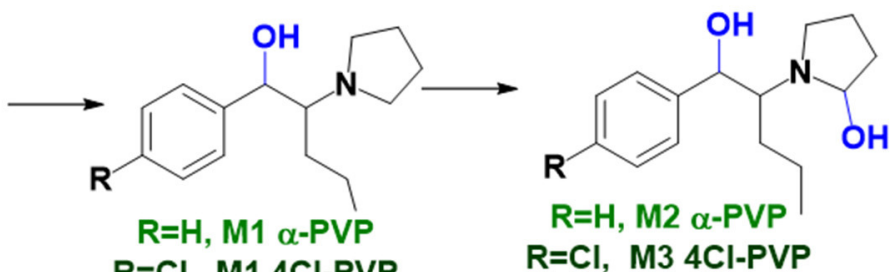

$\mathrm{R}=\mathrm{Cl}$, M1 4Cl-PVP<smiles>[R]c1ccc(C(OCC)C(CCC)N2CCCC2)cc1</smiles>

$\mathrm{R}=\mathrm{Cl}, \mathrm{M} 2 \mathrm{4Cl}-\mathrm{PVP}$<smiles>[R]c1ccc(C(OC)C(CCC)N2CCCC2O)cc1</smiles>

$\mathrm{R}=\mathrm{H}, \mathrm{M} 4 \alpha-\mathrm{PVP}$
$\mathrm{R}=\mathrm{Cl}$, M3 4CI-PVP

\section{Gluc $=$ Glucuronic acid}

FIGURE 2 | Proposed structures of the $\alpha$-PVP and 4CI-PVP Phase I and II metabolites identified by LC-HRMS/MS analysis in HLM and RLM incubations.

Coherently, the product ion displayed by metabolite M4 $\alpha$-PVP is distinct from the one reported by Negreira et al. (2015) for its isomer, resulting from the glucuronidation of the hydroxyl group of the Phase I metabolite stemming from reduction of $\alpha$ PVP combined with a hydroxylation in the pyrrolidine ring and a subsequent oxidation. Interestingly whereas M2 $\alpha$-PVP was only identified in HLM incubations, its Phase II metabolite was identified in both RLM and HLM, thereby suggestion that the parent Phase I metabolite was also formed in RLM.

\section{4'-Chloro- $\alpha$-pyrrolidinovalerophenone (4Cl-PVP)}

4Cl-PVP is a chlorinated derivative of $\boldsymbol{\alpha}$-PVP and, as expected, these two cathinones present similar behaviors when analyzed by LC-HRMS/MS. Presenting the protonated molecule at $\mathrm{m} / \mathrm{z}$ 266.1311 (+1.9 ppm, $\left.\mathrm{C}_{15} \mathrm{H}_{21} \mathrm{ClNO}\right)$, with the chlorine isotopic pattern, the product ion of this cathinone displays at least three fragmentation pathways similar to the ones observed for $\boldsymbol{\alpha}$-PVP (Supplementary Figure 1 vs. Supplementary Figure 6): (1) at $\mathrm{m} / z 195.0568\left(-1.5 \mathrm{ppm}, \mathrm{C}_{11} \mathrm{H}_{13} \mathrm{ClO}\right)$ which is formed upon loss of the pyrrolidine moiety from the parent protonated molecule; (2) at $m / z$ at $126.1304\left(-4.7 \mathrm{ppm}, \mathrm{C}_{8} \mathrm{H}_{16} \mathrm{~N}\right)$, which corresponds to the loss pyrrolidine and alkyl moieties from the protonated molecule; and (3) at $\mathrm{m} / z 138.9957\left(+8.6 \mathrm{ppm}, \mathrm{C}_{7} \mathrm{H}_{4} \mathrm{ClO}\right)$ corresponding to the oxonium ion. Two additional product ions are observed at $\mathrm{m} / z 223.0753\left(2.2 \mathrm{ppm}, \mathrm{C}_{12} \mathrm{H}_{14} \mathrm{ClNO}\right)$, which corresponds to the loss of propyl radical from the protonated molecule, and $\mathrm{m} / z 153.0102$ ( $\left.0 \mathrm{ppm}, \mathrm{C}_{6} \mathrm{H}_{6} \mathrm{ClO}\right)$, stemming from the loss of the pyrrolidine and propyl moieties.

The recognition of the chlorine isotopic cluster was key for the identification of 4Cl-PVP metabolites. Two Phase I and two Phase II metabolites were consistently identified in the RLM and HLM incubations of this cathinone and a third Phase I metabolite, M3 4Cl-PVP, was only identified in HLM incubations (Table 2, Figure 2, Supplementary Figures 7-11).

The Phase I metabolite, M1 4Cl-PVP, exhibits the protonated molecule at $m / z 268.1463\left(0 \mathrm{ppm}, \mathrm{C}_{15} \mathrm{H}_{23} \mathrm{ClNO}\right)$, compatible with the reduction of the carbonyl group of 4Cl-PVP. This constitutes a metabolic transformation very frequent for cathinones (Zaitsu et al., 2014) and is also reported to occur for $\boldsymbol{\alpha}$-PVP, in vivo (Shima et al., 2014). The tandem mass spectrum of this metabolite exhibits two main fragments (Supplementary Figure 7): (1) at $\mathrm{m} / \mathrm{z} 250.1359(+0.8 \mathrm{ppm}$, $\mathrm{C}_{15} \mathrm{H}_{21} \mathrm{ClN}$ ) that stems from the loss of water from the protonated molecule; and (2) at $\mathrm{m} / \mathrm{z} 207.0806(-1.4 \mathrm{ppm}$, $\mathrm{C}_{12} \mathrm{H}_{14} \mathrm{ClN}$ ), which results from the subsequent loss of the propyl radical from the previous fragment ion. This fragmentation pattern is consistent with the one described for the analog $\alpha$ PVP metabolite (Shima et al., 2014; Zaitsu et al., 2014). As stated above, ketone reduction is the major metabolic pathway 
TABLE 2 | Structures of the 4CI-PVP metabolites identified in HLM and RLM incubations by LC-HRMS/MS (ESI+) analysis.

\begin{tabular}{|c|c|c|c|c|c|c|c|c|}
\hline Compound & Structure & $\begin{array}{c}{[\mathrm{M}+\mathrm{H}]^{+}} \\
(m / z)\end{array}$ & $\begin{array}{l}\text { Elemental } \\
\text { composition }\end{array}$ & $\begin{array}{l}\text { Error } \\
\text { (ppm) }\end{array}$ & $\begin{array}{l}\text { Productions } \\
(m / z)\end{array}$ & $\begin{array}{l}\text { Elemental } \\
\text { composition }\end{array}$ & $\begin{array}{l}\text { Error } \\
\text { (ppm) }\end{array}$ & Identification \\
\hline \multirow{5}{*}{ 4Cl-PVP } & & & & & 223.0753 & $\mathrm{C}_{12} \mathrm{H}_{14} \mathrm{CINO}$ & +2.2 & \\
\hline & & & & & 195.0568 & $\mathrm{C}_{11} \mathrm{H}_{13} \mathrm{ClO}$ & -1.5 & \\
\hline & & 266.1311 & $\mathrm{C}_{15} \mathrm{H}_{21} \mathrm{CINO}$ & +1.9 & 153.0102 & $\mathrm{C}_{8} \mathrm{H}_{6} \mathrm{ClO}$ & 0 & \\
\hline & & & & & 138.9957 & $\mathrm{C}_{7} \mathrm{H}_{4} \mathrm{ClO}$ & +8.6 & \\
\hline & & & & & 126.1304 & $\mathrm{C}_{8} \mathrm{H}_{16} \mathrm{~N}$ & -4.7 & \\
\hline
\end{tabular}<smiles>CCCC(C(O)c1ccc(Cl)cc1)N1CCCC1</smiles>

268.1463<smiles>CCCC(C(OC)c1ccc(Cl)cc1)N1CCCC1</smiles>

\section{$444.1786 \quad \mathrm{C}_{21} \mathrm{H}_{31} \mathrm{CINO}_{7} \quad+0.5$}

266.1302

248.1201

206.0738

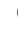

268.1469

250.1371

207.0808

$\mathrm{C}_{15} \mathrm{H}_{23} \mathrm{CINO}$

$\mathrm{C}_{15} \mathrm{H}_{20} \mathrm{CIN}$

$\mathrm{C}_{12} \mathrm{H}_{14} \mathrm{CIN}$

$+2.2$

$+5.6$

$-0.5$

HLM

RLM

M3 4Cl-PVP<smiles>CCCC(C(O)c1ccc(Cl)cc1)N1CCCC1O</smiles>

$284.1413 \quad \mathrm{C}_{15} \mathrm{H}_{23} \mathrm{CINO}_{2} \quad+0.4$

$\mathrm{C}_{15} \mathrm{H}_{21} \mathrm{CINO}$

$\mathrm{C}_{15} \mathrm{H}_{19} \mathrm{CIN}$

$\mathrm{C}_{12} \mathrm{H}_{13} \mathrm{CIN}$

$-1.5$

0

HLM
HLM

RLM<smiles>CCCC(C(=O)c1ccc(Cl)cc1)N1CCCC1O</smiles>

$\mathrm{C}_{15} \mathrm{H}_{19} \mathrm{CINO}$

$+1.9$

142.1233

$\mathrm{C}_{8} \mathrm{H}_{16} \mathrm{NO}$

$+4.9$

HLM

$153.0109 \quad \mathrm{C}_{8} \mathrm{H}_{6} \mathrm{ClO} \quad+4.6 \quad \mathrm{RLM}$

Also shown the corresponding experimental $\mathrm{m} / \mathrm{z}$ values and proposed elemental composition for the protonated molecule and characteristic fragment ions (presented with the associated error in ppm).

reported for other $\alpha$-pyrrolidinophenones in humans, thereby supporting the potential in vivo relevance of this metabolite for 4Cl-PVP. The glucuronide conjugate of M1 4Cl-PVP was also identified. In fact, the neutral loss of $176.0317 \mathrm{u}$ from the protonated molecule of M2 4Cl-PVP $(\mathrm{m} / z$ 444.1786, +0.5 ppm, $\mathrm{C}_{21} \mathrm{H}_{31} \mathrm{ClNO}_{7}$ ), observed in the tandem mass spectrum (Supplementary Figure 8), is indicative of glucuronidation. The observation of two fragment ions at $\mathrm{m} / z 250.1371$ ( $+5.6 \mathrm{ppm}$, 
$\left.\mathrm{C}_{15} \mathrm{H}_{20} \mathrm{ClN}\right)$ and $207.0808\left(-0.5 \mathrm{ppm}, \mathrm{C}_{12} \mathrm{H}_{14} \mathrm{ClN}\right)$, which are also observed in the tandem mass spectrum of 4Cl-PVP M1, further substantiates the assigned structure of M2 4Cl-PVP. The fact that a structurally similar glucuronide derived from $\alpha$-PVP was identified as a urinary metabolite in humans, suggests that this might also be a metabolically relevant pathway for 4Cl-PVP in vivo (Shima et al., 2014).

M3 4Cl-PVP is one additional phase I metabolite that was identified in 4Cl-PVP HLM incubations and results from the hydroxylation of M1 4Cl-PVP. Exhibiting the protonated molecule at $m / z 284.1413$ (+0.4 ppm, $\mathrm{C}_{15} \mathrm{H}_{23} \mathrm{ClNO}_{2}$ ), M3 4Cl-PVP displays diagnostic product ions (Supplementary Figure 9), corresponding to two consecutive losses of water: at $\mathrm{m} / z 266.1302\left(-1.5 \mathrm{ppm}, \mathrm{C}_{15} \mathrm{H}_{21} \mathrm{ClNO}\right)$ and $248.1201\left(0 \mathrm{ppm}, \mathrm{C}_{15} \mathrm{H}_{19} \mathrm{ClN}\right)$. The subsequent loss of the alkyl chain is also observed at $\mathrm{m} / z 206.0738(+0.5 \mathrm{ppm}$, $\mathrm{C}_{12} \mathrm{H}_{13} \mathrm{ClN}$ ). Whereas the product ion obtained does not allow the identification of the exact location of the hydroxyl group, the $2^{\prime}$ position of the pyrrolidine is suggested, since it is a frequent hydroxylation site for other $\alpha$-pyrrolidinophenones, including $\boldsymbol{\alpha}$-PVP (Tyrkkö et al., 2013; Negreira et al., 2015). A similar metabolic transformation was also reported for PV8 $(\alpha-$ pyrrolidinoheptaphenone) (Swortwood et al., 2016), a cathinone analog closely resembling $\alpha$-PVP.

The mass increase of $15.994 \mathrm{u}$ from 4Cl-PVP observed for the protonated molecule of M4 4Cl-PVP, at $\mathrm{m} / z 282.1256(-0.4$ ppm, $\mathrm{C}_{15} \mathrm{H}_{21} \mathrm{ClNO}_{2}$ ), is indicative of direct hydroxylation of the parent cathinone. The observation of the product ion at $\mathrm{m} / \mathrm{z}$ $142.1233\left(+4.9 \mathrm{ppm}, \mathrm{C}_{8} \mathrm{H}_{16} \mathrm{NO}\right.$ ) (Supplementary Figure 10), suggests that this metabolite stems from the hydroxylation of the pyrodilidine or alkyl moieties. Coherently, these hydroxylation locations are also reported for $\boldsymbol{\alpha}$-PVP in vivo (Tyrkkö et al., 2013). Nonetheless, the consistent identification of the glucuronide M5 4Cl-PVP in HLM and RLM incubations suggests that the most probable location of hydroxylation in M4 4Cl-PVP is the pyrrolidine ring. In fact, the tandem mass spectrum of M5 4Cl-PVP protonated molecule, at $\mathrm{m} / z 458.1580$ (+ $0.9 \mathrm{ppm}$,
$\mathrm{C}_{21} \mathrm{H}_{29} \mathrm{ClNO}_{8}$ ), exhibits a product ion at $\mathrm{m} / z 195.0568(-1.5$ ppm, $\mathrm{C}_{11} \mathrm{H}_{12} \mathrm{ClO}$ ) (Supplementary Figure 11), which results from the loss of hydroxylated and glucuronidated pyrrolidine moiety from the protonated molecule, thereby evidencing that this Phase II metabolite stems from the glucuronidation of M4 4Cl-PVP, bearing the hydroxyl group in the pyrrolidine moiety (Figure 2). Of note is the fact that this metabolic pathway is also observed for $\alpha$-PVP.

\section{4'-Methyl- N,N-dimethylcathinone (4-MDMC)}

The protonated molecule of 4-MDMC is observed at $\mathrm{m} / z$ 192.1374 (-4.7 ppm, $\mathrm{C}_{12} \mathrm{H}_{18} \mathrm{NO}$ ) (Table 3) and its tandem mass spectrum presents a base peak at $\mathrm{m} / z 119.0877(+0.2$ ppm, $\mathrm{C}_{9} \mathrm{H}_{11}$ ) (Supplementary Figure 12). This fragment ion was already reported for mephedrone (4-MMC), when analyzed by LC-HRMS (Pozo et al., 2015), and may be explained on basis of a neutral loss containing the nitrogen after dissociation of the $\mathrm{C}$ $\mathrm{N}$ bond from the protonated molecule, followed by CO loss. The possibility of subsequently undergoing rearrangement, with the formation of a seven-membered ring, may explain the conferred stability of this fragment (Zuba, 2012; Pedersen et al., 2013).

Whereas, no Phase I metabolites were identified in 4-MDMC incubations run in the presence of Phase I cofactors, one signal at $\mathrm{m} / z 370.1488\left(-2.1 \mathrm{ppm}, \mathrm{C}_{17} \mathrm{H}_{24} \mathrm{NO}_{8}\right)$, compatible with the glucuronide conjugate M1 4-MDMC (Table 3, Figure 3), was identified following LC-HRMS analysis of alamethicininduced RLM incubations run in the presence of Phase I and II cofactors. M1 4-MDMC is compatible with the glucuronidation of a 4-MDMC Phase I metabolite that stems from two consecutive metabolic transformations (Figure 3): 4MDMC demethylation, yielding mephedrone (4-MMC), which is subsequently hydroxylated in a methyl group. In fact, the tandem mass spectrum of M1 4-MDMC metabolite displays a very similar product ion profile to the one reported by Pozo et al. (2015) for a 4-MMC Phase II metabolite, which was identified

TABLE 3 | Structures for 4-MDMC and its Phase II metabolite identified in HLM and RLM incubations by LC-HRMS/MS (ESI+) analysis.

\begin{tabular}{|c|c|c|c|c|c|c|c|c|}
\hline Compound & Structure & $\begin{array}{c}{[\mathrm{M}+\mathrm{H}]^{+}} \\
(\mathrm{m} / \mathrm{z})\end{array}$ & $\begin{array}{l}\text { Elemental } \\
\text { composition }\end{array}$ & Error (ppm) & $\begin{array}{c}\text { Product } \\
\text { ions }(m / z)\end{array}$ & $\begin{array}{l}\text { Elemental } \\
\text { composition }\end{array}$ & Error (ppm) & identification \\
\hline 4-MDMC & & 192.1374 & $\mathrm{C}_{12} \mathrm{H}_{18} \mathrm{NO}$ & -4.7 & 119.0877 & $\mathrm{C}_{9} \mathrm{H}_{11}$ & +0.2 & - \\
\hline M1 4-MDMC & & 370.1488 & $\mathrm{C}_{17} \mathrm{H}_{24} \mathrm{NO}_{8}$ & -2.1 & $\begin{array}{l}194.1167 \\
178.1229 \\
160.1121\end{array}$ & $\begin{array}{c}\mathrm{C}_{11} \mathrm{H}_{16} \mathrm{NO}_{2} \\
\mathrm{C}_{11} \mathrm{H}_{16} \mathrm{NO} \\
\mathrm{C}_{11} \mathrm{H}_{14} \mathrm{~N}\end{array}$ & $\begin{array}{c}-4.6 \\
+1.7 \\
0\end{array}$ & RLM \\
\hline
\end{tabular}

Also shown the corresponding experimental $\mathrm{m} / \mathrm{z}$ values and proposed elemental composition for the protonated molecule and characteristic fragment ions (presented with the associated error in ppm). 


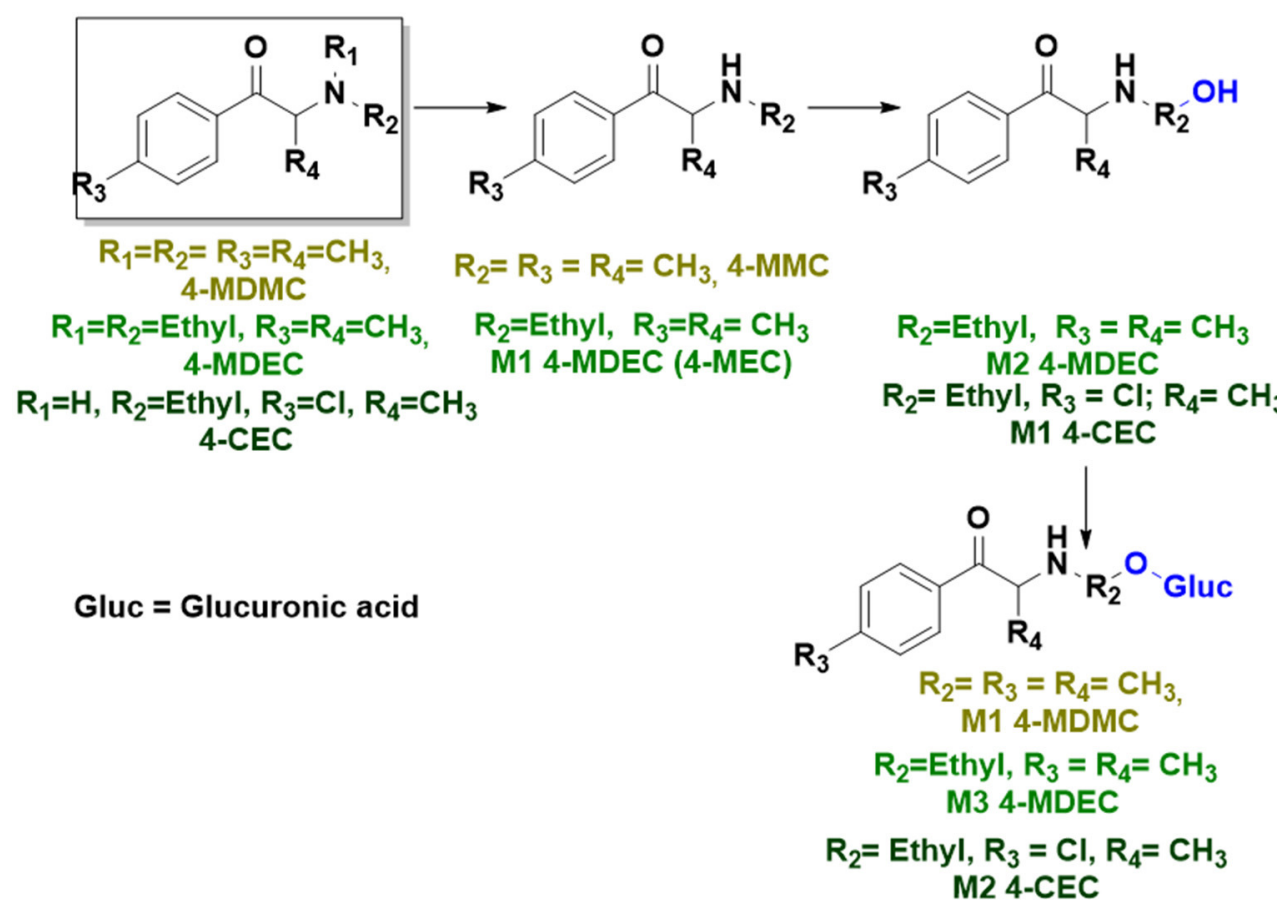

FIGURE 3 | Proposed structures for the metabolites identified by LC-HRMS/MS in RLM and HLM incubations of 4-MDMC, 4-MDEC, and 4-CEC

in the urine of two human volunteers that ingested $200 \mathrm{mg} \mathrm{4-}$ MMC orally (Pozo et al., 2015). However, whereas these authors suggest that C3 is the most probable hydroxylation site, the hydroxyl group is more likely to be at the $N$-methyl substituent. In fact, $N$-alkyl groups are considered hot spots for metabolic hydroxylation, which constitutes the first step of $N$-dealkylation that is a common metabolic pathway for substituted amines (Trager, 2007). Coherently, similarly to what was reported for this glucuronide metabolite of 4-MMC, the tandem mass spectrum of the glucuronide M1 4-MDMC exhibits a base peak at $\mathrm{m} / z$ 194.1167 (-4.6 ppm, $\mathrm{C}_{11} \mathrm{H}_{16} \mathrm{NO}_{2}$ ) (Supplementary Figure 13) that results from the neutral loss of $176.0321 \mathrm{u}$ from the protonated molecule, corresponding to typical the glucuronide loss. Two other minor product ions are observed at $\mathrm{m} / z 178.1229$ $\left(+1.7\right.$ ppm, $\left.\mathrm{C}_{11} \mathrm{H}_{16} \mathrm{NO}\right)$ and $160.1121\left(0 \mathrm{ppm}, \mathrm{C}_{11} \mathrm{H}_{14} \mathrm{~N}\right)$, which can be explained by a mechanism similar to the one proposed by Pozo et al. (2015) (Supplementary Figure 13) for the glucuronide conjugate of the hydroxylated metabolite of 4MMC. Regardless of the exact location of hydroxylation of this phase I metabolite, our results suggest that 4-MDMC may act as a prodrug of 4-MMC. This constitutes an issue of concern taking into consideration the number of 4-MMC-related fatalities (Busardò et al., 2015). In fact, with a very narrow safety window, 4-MMC dosages that fall within the recreational use limits are suggested to be potentially fatal, in particular when combined with other drugs (Busardò et al., 2015). Aditionally, the fact that no 4-MDMC was identified in the incubation where M1 4-MDMC was identified, suggests that this might constitute an important metabolic pathway for 4-MDMC.

\section{4'-Methyl-N,N-diethylcathinone (4-MDEC)}

The protonated molecule of 4-MDEC was observed at $\mathrm{m} / z$ $220.1697\left(+0.5 \mathrm{ppm}, \mathrm{C}_{14} \mathrm{H}_{22} \mathrm{NO}\right)$ (Table 4) and whereas the fragment ion stemming from the loss of a first $N$ ethyl group is not observed in the tandem mass spectrum (Supplementary Figure 14), this constitutes the first loss undergone by this cathinone, at the experimental conditions used. In fact, the fragment ion at $\mathrm{m} / z 174.1270(-4.0 \mathrm{ppm}$, $\mathrm{C}_{12} \mathrm{H}_{16} \mathrm{~N}$ ) is formed water by loss from this first product ion, a fragmentation pathway which is characteristic of other cathinones (Namera et al., 2015). The subsequent loss of $\mathrm{CH}_{3}$ radical explains the formation of the fragment ion at $\mathrm{m} / \mathrm{z}$ $159.1044\left(+0.6 \mathrm{ppm}, \mathrm{C}_{10} \mathrm{H}_{12} \mathrm{~N}\right)$. Whereas the formation of radical ions is not a frequent mechanism when using ESI (Thurman et al., 2007), it seems to be particularly frequent on the LC-HRMS analysis of cathinones. In fact, this kind of fragmentation was already reported for 4-MMC and was consistently observed in the fragmentation pattern of the glucuronide M1 4-MDMC (see above) (Namera et al., 2015). Likewise, the in-source rearrangement to a indole ring that was already used to explain 4-MMC fragmentation (Pozo et al., 2015), followed by loss of the ethyl radical, can also be evoked to explain the formation of the product ion at 144.0813 (-3.5 ppm, $\left.\mathrm{C}_{10} \mathrm{H}_{10} \mathrm{~N}\right)$ observed in the 4-MDEC tandem mass spectrum.

Two Phase I metabolites were consistently identified in 4-MDEC HLM and RLM incubations (Table 4, Figure 3, Supplementary Figures 15, 16). The protonated molecule of M1 4-MDEC was observed at $m / z 192.1378$ (-2.6 ppm, $\left.\mathrm{C}_{12} \mathrm{H}_{18} \mathrm{NO}\right)$, 
TABLE 4 | Structures of the 4-MDEC metabolites identified in HLM and RLM incubations by LC-HRMS/MS (ESI+) analysis.

\begin{tabular}{|c|c|c|c|c|c|c|c|c|}
\hline Compound & Structure & {$[\mathrm{M}+\mathrm{H}]^{+}(\mathrm{m} / \mathrm{z})$} & $\begin{array}{l}\text { Elemental } \\
\text { composition }\end{array}$ & Error (ppm) & $\begin{array}{c}\text { Product } \\
\text { ions }(m / z)\end{array}$ & $\begin{array}{l}\text { Elemental } \\
\text { composition }\end{array}$ & Error (ppm) & Identification \\
\hline 4-MDEC & & 220.1697 & $\mathrm{C}_{14} \mathrm{H}_{22} \mathrm{NO}$ & +0.5 & $\begin{array}{l}174.1270 \\
159.1044 \\
144.0813\end{array}$ & $\begin{array}{l}\mathrm{C}_{12} \mathrm{H}_{16} \mathrm{~N} \\
\mathrm{C}_{10} \mathrm{H}_{12} \mathrm{~N} \\
\mathrm{C}_{10} \mathrm{H}_{10} \mathrm{~N}\end{array}$ & $\begin{array}{c}4.0 \\
+0.6 \\
-3.5\end{array}$ & - \\
\hline M1 4-MDEC & & 192.1378 & $\mathrm{C}_{12} \mathrm{H}_{18} \mathrm{NO}$ & -2.6 & 144.0812 & $\mathrm{C}_{10} \mathrm{H}_{10} \mathrm{~N}$ & +2.8 & $\begin{array}{l}\text { HLM } \\
\text { RLM }\end{array}$ \\
\hline M2 4-MDEC & & 208.1329 & $\mathrm{C}_{12} \mathrm{H}_{18} \mathrm{NO}_{2}$ & +1.4 & $\begin{array}{l}172.1128 \\
144.0813\end{array}$ & $\begin{array}{l}\mathrm{C}_{12} \mathrm{H}_{14} \mathrm{~N} \\
\mathrm{C}_{10} \mathrm{H}_{10} \mathrm{~N}\end{array}$ & $\begin{array}{l}+4.1 \\
+3.5\end{array}$ & $\begin{array}{l}\text { HLM } \\
\text { RLM }\end{array}$ \\
\hline M3 4-MDEC & & 384.1637 & $\mathrm{C}_{18} \mathrm{H}_{26} \mathrm{NO}_{8}$ & +4.1 & $\begin{array}{c}208.1337 \\
172.1124\end{array}$ & $\begin{array}{c}\mathrm{C}_{12} \mathrm{H}_{18} \mathrm{NO}_{2} \\
\mathrm{C}_{12} \mathrm{H}_{14} \mathrm{~N}\end{array}$ & $\begin{array}{l}+2.4 \\
+1.7\end{array}$ & RLM \\
\hline
\end{tabular}

Also shown the corresponding experimental $\mathrm{m} / \mathrm{z}$ values and proposed elemental composition for the protonated molecule and characteristic fragment ions (presented with the associated error in ppm).

which is compatible with the protonated molecule 4-MEC. This product of deethylation of 4-MDEC is also a controlled drug that have been linked with several overdose cases (Gil et al., 2013; Rojek et al., 2014). However, contrary to what was reported by Helfer et al. (2015), the initial fragmentation step of 4-MEC was not the loss of water. In fact, at the experimental conditions used, the base peak of the tandem mass spectrum of M1 4-MDEC (4MEC) was observed at $m / z 144.0812\left(-2.8 \mathrm{ppm}, \mathrm{C}_{12} \mathrm{H}_{18} \mathrm{NO}\right)$ which stems from the loss of $48.0566 \mathrm{u}$ from the protonated molecule. In accordance with what was already discussed, the formation of a more stable indole system can be postulated for the formation of this product ion (Supplementary Figure 15). This suggests that 4-MDEC is metabolically converted into the controlled psychotic substance 4-MEC.

One additional Phase I metabolite, M2 4-MDEC, was observed at $m / z 208.1329\left(-1.4 \mathrm{ppm}, \mathrm{C}_{12} \mathrm{H}_{18} \mathrm{NO}_{2}\right.$ ). The mass increment of $15.9944 \mathrm{u}$ from M1 4-MDEC (4-MEC), suggests that M2 4-MDEC was formed upon hydroxylation of 4MEC. A similar metabolite was identified by Helfer et al. (2015) upon GC-MS analysis of 4-MEC incubations in HLM. Whereas the location for 4-MEC hydroxylation is proposed to be the methyl substituent of the aromatic moiety (Helfer et al., 2015), no LC-HRMS data is provided for this metabolite, thereby precluding any comparison with our data. Nonetheless, the fact that the base peak, at $m / z 144.0823$ ( $+3.5 \mathrm{ppm}$, $\mathrm{C}_{10} \mathrm{H}_{10} \mathrm{~N}$ ), of the M2 4-MDEC tandem mass spectrum is the same observed for M1 4-MDEC (Supplementary Figure 16 vs. Supplementary Figure 15), suggests that this metabolite results from hydroxylation at the $N$-ethyl substituent. M3 4-MDEC is one additional Phase II metabolite that was identified in RLM incubations (Table 4, Figure 3). The protonated molecule of this glucuronide is displayed at $\mathrm{m} / z 384.1637$ (+4.1 ppm, $\mathrm{C}_{18} \mathrm{H}_{26} \mathrm{NO}_{8}$ ) and the tandem mass spectrum of this ion (Supplementary Figure 17) shows the characteristic loss of the glucuronide moiety $(176.0300 \mathrm{u})$ at $\mathrm{m} / \mathrm{z} 208.1337(+2.4 \mathrm{ppm}$, $\mathrm{C}_{12} \mathrm{H}_{18} \mathrm{NO}_{2}$ ). One additional fragment ion is observed at $\mathrm{m} / z$ $172.1124\left(+1.7 \mathrm{ppm}, \mathrm{C}_{12} \mathrm{H}_{14} \mathrm{~N}\right)$, stemming from two consecutive losses of water. Taking into consideration that the same fragment ion is also observed in the tandem spectrum of M2 4-MDEC, M3 4-MDEC is suggested to be the glucuronic acid conjugate of this Phase I metabolite. The fact that no parent cathinone was detected in the incubations where this Phase II metabolite was identified, suggests that this might constitute a relevant metabolic pathway of 4-MDEC. 


\section{4'-Chloro-N-ethylcathinone (4-CEC)}

The protonated molecule of 4-CEC is observed at $\mathrm{m} / z 212.0837$ (0 ppm, $\mathrm{C}_{11} \mathrm{H}_{15} \mathrm{ClNO}$ ), exhibiting the chlorine isotope cluster. This isotopic pattern is also observed in the first product ion at $m / z 164.0252\left(-5.5 \mathrm{ppm}, \mathrm{C}_{9} \mathrm{H}_{7} \mathrm{ClN}\right)$, corresponding to the rearrangement product to an indole ring, following the loss of $N$-substituent and water from the protonated molecule (Supplementary Figure 18) (Nóbrega and Dinis-Oliveira, 2018). The fragment ion at $\mathrm{m} / z 159.1036\left(-3.8 \mathrm{ppm}, \mathrm{C}_{11} \mathrm{H}_{13} \mathrm{~N}\right)$ is formed from the consecutive loss of $\mathrm{Cl}$ radical and water from the protonated molecule. The subsequent loss of $\mathrm{CH}_{3}$ radical, explains the formation of the base peak, at $m / z 144.0813(+3.5$ ppm, $\left.\mathrm{C}_{10} \mathrm{H}_{10} \mathrm{~N}\right)$.

A first attempt to investigate the metabolic profile of 4CEC was performed in human hepatocytes (Fabregat-Safont et al., 2020). However, no metabolites were identified for this cathinone in this in vitro system. Nonetheless, Wagmann et al. (2020) reported the metabolic profile of this cathinone in liver microsome and S9 fraction incubations, thereby enabling the identification of several Phase I and Phase II metabolites. In the current work, the recognition of the chlorine isotopic cluster, and the use of the Data Analysis isotope Cluster analysis tool, were key for the identification of additional Phase I and Phase II metabolites of 4-CEC that were identified in RLM incubations (Table 5, Figure 3, Supplementary Figures 19, 20). M1 4-CEC metabolite, presents a mass increase of $15.9942 \mathrm{u}$ from 4-CEC, exhibiting the protonated molecule at $m / z 228.0779\left(-3.1 \mathrm{ppm}, \mathrm{C}_{11} \mathrm{H}_{15} \mathrm{ClNO}_{2}\right)$ (Supplementary Figure 19). This mass increase is compatible with a hydroxylation. The observation of the base fragment ion at $m / z 138.9947\left(+1.4 \mathrm{ppm}, \mathrm{C}_{7} \mathrm{H}_{4} \mathrm{ClO}\right)$, corresponding to the oxonium ion, suggests that hydroxylation occurred in one of the alkyl carbons of 4-CEC. Therefore, taking into consideration the arguments presented for the hydroxylation location of M2 4-MDMC, the $N$-ethyl group of M1 4-CEC was suggested as the most likely hydroxyl location. The glucuronide conjugate of this Phase II metabolite, M2 4-CEC, was also identified. Coherently, the protonated molecule of M2 4-CEC, $\mathrm{m} / z 404.1104\left(+0.7 \mathrm{ppm}, \mathrm{C}_{17} \mathrm{H}_{23} \mathrm{ClNO}_{8}\right.$ ), displays a product ion at $\mathrm{m} / z 228.0780\left(+2.6 \mathrm{ppm}, \mathrm{C}_{11} \mathrm{H}_{15} \mathrm{ClNO}_{2}\right)$, corresponding to the loss of the glucuronic acid moiety from the protonated molecule (Supplementary Figure 20). Importantly, none of these metabolites were reported by Wagmann et al. (2020). As stated above, taking into consideration the group experience (Godinho et al., 2018), the fact that these metabolites were solely identified in RLM does not necessarily imply that they cannot be also formed in humans, in vivo.

\section{CONCLUSION}

Using LC-HRMS/MS analysis of HLM and RLM incubations multiple Phase I and glucoronide metabolites were identified for the selected synthetic cathinones: -4CI-PVP, 4-CEC, 4MDEC, and 4-MDMC. Specifically: (1) four Phase I and two Phase II metabolites were identified for the chlorinated derivative of $\alpha$-PVP, 4Cl-PVP; (2) one Phase I and one glucuronide conjugate were identified in RLM for 4-CEC, which is among the most seized cathinones in 2017; (3) two Phase I and one

TABLE 5 | Structures of the 4-CEC metabolites identified in RLM incubations by LC-HRMS/MS (ESI+) analysis.

Compound Structure<smiles>CCNC(C)C(=O)c1ccc(Cl)cc1</smiles>

M1 4-CEC<smiles>CC(O)NC(C)C(=O)c1ccc(Cl)cc1</smiles>

M2 4-CEC<smiles>CC(C)NC(C)C(=O)c1ccc(Cl)cc1</smiles>

$[\mathrm{M}+\mathrm{H}]^{+}(\mathrm{m} / \mathrm{z}) \begin{gathered}\text { Elemental } \\ \text { composition }\end{gathered}$

212.0837

$\mathrm{C}_{11} \mathrm{H}_{15} \mathrm{CINO}$

0

228.0779

$\mathrm{C}_{11} \mathrm{H}_{15} \mathrm{CINO}_{2}$

$-3.1$

138.9947

$\mathrm{C}_{7} \mathrm{H}_{4} \mathrm{ClO}$

$+1.4$

RLM

404.1104

\section{$(\mathrm{m} / \mathrm{z})$}

composition

$\begin{array}{ll}\mathrm{C}_{9} \mathrm{H}_{7} \mathrm{ClN} & +5.5 \\ \mathrm{C}_{11} \mathrm{H}_{13} \mathrm{~N} & -3.8 \\ \mathrm{C}_{10} \mathrm{H}_{10} \mathrm{~N} & +3.5\end{array}$

Error (ppm) Identification 
Phase II metabolites were identified for 4-MDEC; and (4) one Phase II metabolite was identified for 4-MDMC. Additionally, a new Phase II conjugate, derived from the recreational drug $\alpha$-PVP, was herein identified for the first time. Of note is the fact that this metabolic pathway, consisting on hydroxylation of the alkyl nitrogen substituent, followed by glucuronidation, was consistently observed in all cathinones studied in the current work. The reduction of the carbonyl group constituted one additional metabolic pathway for pyrrolidinic cathinones. Whereas, the metabolic profiles of these cathinones were obtained in vitro, the identification of metabolites stemming from metabolic pathways frequently identified in vivo for this class of compounds, suggests the likelihood of a similar metabolic profile being observed in vivo. Also noteworthy is the fact that our results suggest that 4-MDMC and 4-MDEC might act as prodrugs of the controlled substances 4-MMC and 4-MEC, respectively. These findings constitute an important contribute not only for the unequivocal proof of the intake of these recently reported synthetic cathinones but also to understand their potential adverse effects and link causative agents to toxicities.

\section{DATA AVAILABILITY STATEMENT}

The original contributions presented in the study are included in the article/Supplementary Material, further inquiries can be directed to the corresponding author/s.

\section{REFERENCES}

Antunes, M., Sequeira, M., de Caires Pereira, M., Caldeira, M. J., Santos, S., Franco, J., et al. (2020). Determination of selected cathinones in blood by solid-phase extraction and GC-MS. J. Anal. Toxicol. doi: 10.1093/jat/bkaa074. [Epub ahead of print].

Arias, H. R., Santamaría, A., and Ali, S. F. (2009). Pharmacological and neurotoxicological actions mediated by bupropion and diethylpropion. Int. Rev. Neurobiol. 88, 223-255. doi: 10.1016/S0074-7742(09)88009-4

Busardò, F. P., Kyriakou, C., Napoletano, S., Marinelli, E., and Zaami, S. (2015). Mephedrone related fatalities: a review. Eur. Rev. Med. Pharmacol. Sci. 19, 3777-3790.

Carroll, F. I., Blough, B. E., Mascarella, S. W., Navarro, H. A., Lukas, R. J., and Damaj, M. I. (2014). Bupropion and bupropion analogs as treatments for CNS disorders, Adv. Pharmacol. 69, 177-216. doi: 10.1016/B978-0-12-420118-7.00005-6

Costa, R., Oliveira, N. G., and Dinis-Oliveira, R. J. (2019). Pharmacokinetic and pharmacodynamic of bupropion: integrative overview of relevant clinical and forensic aspects. Drug Metab. Rev. 51, 293-313. doi: 10.1080/03602532.2019.1620763

Ellefsen, K. N., Concheiro, M., and Huestis, M. A. (2016). Synthetic cathinone pharmacokinetics, analytical methods, and toxicological findings from human performance and postmortem cases. Drug Metab. Rev. 48, 237-265. doi: 10.1080/03602532.2016.1188937

EMCDDA (2015). EMCDDA-Europol 2014 Annual Report on the Implementation of Council Decision 2005/387/JHA. Available online at: https://www.emcdda. europa.eu/publications/implementation-reports/2014_en (accessed September $15,2020)$.

EMCDDA (2016). EMCDDA-Europol 2015 Annual Report on the Implementation of Council Decision 2005/387/JHA. Available online at: https://www.emcdda. europa.eu/publications/implementation-reports/2015_en (accessed September $15,2020)$.

\section{AUTHOR CONTRIBUTIONS}

HG and AA planned the work, interpreted the data, and wrote the article. BL performed the experimental and data processing steps. MC critically revised the manuscript. All authors approved the final version of the manuscript.

\section{FUNDING}

We thank FCT (Fundação para a Ciência e Tecnologia) for funding the strategic projects UIDB/00100/2020 and UIDP/00100/2020 to CQE - Centro de Química Estrutural, UIDB/04046/2020 and UIDP/04046/2020 to BioISI - Biosystems \& Integrative Sciences Institute, UIDB/04292/2020 and UIDP/04292/2020 to MARE - Marine and Environmental Sciences Centre, and the research projects PTDC/QUIQAN/32242/2017, PTDC/QUI-QIN/28662/2017, PTDC/QUI-QOR/29664/2017, and POINT4PAC project (SAICTPAC/0019/2015-LISBOA-01-0145-FEDER-016405).

\section{SUPPLEMENTARY MATERIAL}

The Supplementary Material for this article can be found online at: https://www.frontiersin.org/articles/10.3389/fchem. 2020.609251/full\#supplementary-material

EMCDDA (2017). EMCDDA-Europol 2016 Annual Report on the Implementation of Council Decision 2005/387/JHA. Available online at: https://www.emcdda. europa.eu/publications/implementation-reports/2016_el (accessed September $15,2020)$.

EMCDDA (2020). European Drug Report 2020: Trends and Developments. Available online at: https://www.emcdda.europa.eu/publications/edr/trendsdevelopments/2020_en (accessed September 15, 2020).

EMCDDA and EUROPOL (2019). EU Drug Markets Report 2019. Available online at: https://www.emcdda.europa.eu/publications/joint-publications/eudrug-markets-report-2019_en (accessed September 15, 2020).

EU (2017). DIRECTIVE (EU) 2017/2103 Of The European Parliament and of the Council of 15 November 2017 amending Council Framework Decision 2004/757/JHA in order to include new psychoactive substances in the definition of "drug" and repealing Council Decision 2005/387. Off. J. Euro. Union 305, $12-18$.

Fabregat-Safont, D., Mardal, M., Sancho, J. V., Hernández, F., Linnet, K., and Ibáñez, M. (2020). Metabolic profiling of four synthetic stimulants, including the novel indanyl-cathinone 5-PPDi, after human hepatocyte incubation. J. Pharm. Anal. 10, 147-156. doi: 10.1016/j.jpha.2019. 12.006

FDA (2020).Drugs@FDA: FDA-Approved Drugs. Available online at: https://www. accessdata.fda.gov/scripts/cder/daf/ (accessed September 15, 2020).

Fisher, M. B., Campanale, K., Ackermann, B. L., Vandenbranden, M., and Wrighton, S. A. (2000). In vitro glucuronidation using human liver microsomes and the pore- forming peptide alamethicin. Drug Metab. Dispos. 28, 560-566.

Gaspar, H., Bronze, S., Oliveira, C., Victor, B. L., Machuqueiro, M., Pacheco, R., et al. (2018). Proactive response to tackle the threat of emerging drugs: synthesis and toxicity evaluation of new cathinones. Forensic. Sci. Int. 290, 146-156. doi: 10.1016/j.forsciint.2018.07.001

German, C. L., Fleckenstein, A. E., and Hanson, G. R. (2014). Bath salts and synthetic cathinones: an emerging designer drug phenomenon. Life Sci. 97, 2-8. doi: 10.1016/j.lfs.2013.07.023 
Gil, D., Adamowicz, P., Skulska, A., Tokarczyk, B., and Stanaszek, R. (2013). Analysis of 4-MEC in biological and non-biological material-three case reports. Forensic Sci. Int. 228, e11-15. doi: 10.1016/j.forsciint.2013.03.011

Godinho, A. L. A., Martins, I. L., Nunes, J., Charneira, C., Grilo, J., Silva, D. M., et al. (2018). High resolution mass spectrometry-based methodologies for identification of Etravirine bioactivation to reactive metabolites: in vitro and in vivo approaches. Eur. J. Pharm. Sci. 119, 70-82. doi: 10.1016/j.ejps.2018.03.026

Helfer, A. G., Turcant, A., Boels, D., Ferec, S., Lelièvre, B., Welter, J., et al. (2015). Elucidation of the metabolites of the novel psychoactive substance 4-methyl$\mathrm{N}$-ethyl-cathinone (4-MEC) in human urine and pooled liver microsomes by GC-MS and LC-HR-MS/MS techniques and of its detectability by GCMS or LC-MSn standard screening approaches. Drug Test. Anal. 7, 368-375. doi: 10.1002/dta.1682

Kang, J. G., and Park, C. Y. (2012). Anti-obesity drugs: a review about their effects and safety. Diabetes Metab. J. 36, 13-25. doi: 10.4093/dmj.2012.36.1.13

Kelly, J. P. (2011). Cathinone derivatives: a review of their chemistry, pharmacology and toxicology. Drug Test. Anal. 3, 439-453. doi: $10.1002 /$ dta.313

Meyer, M. R., Du, P., Schuster, F., and Maurer, H. H. (2010). Studies on the metabolism of the $\alpha$-pyrrolidinophenone designer drug methylenedioxypyrovalerone (MDPV) in rat and human urine and human liver microsomes using GC-MS and LC-high-resolution MS and its detectability in urine by GC-MS. J. Mass Spectrom. 45, 1426-1442. doi: 10.1002/jms.1859

Meyer, M. R., Vollmar, C., Schwaninger, A. E., Wolf, E. U., and Maurer, H. H. (2012). New cathinone-derived designer drugs 3-bromomethcathinone and 3fluoromethcathinone: studies on their metabolism in rat urine and human liver microsomes using GC-MS and LC-high-resolution MS and their detectability in urine. J. Mass Spectrom. 47, 253-262. doi: 10.1002/jms.2960

Meyer, R. M., and Maurer, H. H. (2010). Metabolism of designer drugs of abuse: an updated review. Curr. Drug Metab. 11, 468-482. doi: 10.2174/138920010791526042

Namera, A., Kawamura, M., Nakamoto, A., Saito, T., and Nagao, M. (2015). Comprehensive review of the detection methods for synthetic cannabinoids and cathinones. Forensic. Toxicol. 33, 175-194. doi: 10.1007/s11419-015-0270-0

Negreira, N., Erratico, C., Kosjek, T., van Nuijs, A. L. N., Heath, E., Neels, H., et al. (2015). In vitro phase I and phase II metabolism of $\alpha$-pyrrolidinovalerophenone ( $\alpha$-PVP), methylenedioxypyrovalerone (MDPV) and methedrone by human liver microsomes and human liver cytosol. Anal. Bioanal. Chem. 407, 5803-5816. doi: 10.1007/s00216-015-8763-6

Nóbrega, L., and Dinis-Oliveira, R. J. (2018). The synthetic cathinone $\alpha$ pyrrolidinovalerophenone $(\alpha-\mathrm{PVP})$ : pharmacokinetic and pharmacodynamic clinical and forensic aspects. Drug Metab. Rev. 50, 125-139. doi: 10.1080/03602532.2018.1448867

Onakpoya, I. J., Heneghan, C. J., and Aronson, J. K. (2016). Postmarketing withdrawal of anti-obesity medicinal products because of adverse drug reactions: a systematic review. BMC Med. 14, 1-10. doi: 10.1186/s12916-016-0735-y

Pedersen, A. J., Reitzel, L. A., Johansen, S. S., and Linnet, K. (2013). In vitro metabolism studies on mephedrone and analysis of forensic cases. Drug Test. Anal. 5, 430-438. doi: 10.1002/dta.1369

Pieprzyca, E., Skowronek, R., NiŽnanský, L., and Czekaj, P. (2020). Synthetic cathinones - from natural plant stimulant to new drug of abuse. Eur. J. Pharmacol. 875:173012. doi: 10.1016/j.ejphar.2020.173012

Pozo, Ó. J., Ibáñez, M., Sancho, J. V., Lahoz-Beneytez, J., Farré, M., Papaseit, E., et al. (2015). Mass spectrometric evaluation of mephedrone in vivo human metabolism: Identification of phase I and phase II metabolites, including a novel succinyl conjugate. Drug Metab. Dispos. 43, 248-257. doi: $10.1124 / \mathrm{dmd} .114 .061416$

Prosser, J. M., and Nelson, L. S. (2012). The toxicology of bath salts: a review of synthetic cathinones. J. Med. Toxicol. 8, 33-42. doi: 10.1007/s13181-011-0193-z

Rojek, S., Klys, M., Maciów-Glab, M., Kula, K., and Strona, M. (2014). Cathinones derivatives-related deaths as exemplified by two fatal cases involving methcathinone with 4-methylmethcathinone and 4-methylethcathinone. Drug Test. Anal. 6, 770-777. doi: 10.1002/dta.1615

Shima, N., Katagi, M., Kamata, H., Matsuta, S., Sasaki, K., Kamata, T., et al. (2014). Metabolism of the newly encountered designer drug $\alpha$ - pyrrolidinovalerophenone in humans: Identification and quantitation of urinary metabolites. Forensic. Toxicol. 32, 59-67. doi: 10.1007/s11419-013-0202-9

Strano-Rossi, S., Cadwallader, A. B., de la Torre, X., and Botrè, F. (2010). Toxicological determination and in vitro metabolism of the designer drug methylenedioxypyrovalerone (MPDV) by gas chromatography/mass spectrometry and liquid chromatography/quadrupole time-of-flight mass spectrometry. Rapid Commun. Mass Spectrom. 24, 2706-2714. doi: $10.1002 / \mathrm{rcm} .4692$

Swortwood, M. J., Ellefsen, K. N., Wohlfarth, A., Diao, X., ConcheiroGuisan, M., Kronstrand, R., et al. (2016). First metabolic profile of PV8, a novel synthetic cathinone, in human hepatocytes and urine by high-resolution mass spectrometry. Anal. Bioanal. Chem. 408, 4845-4856. doi: $10.1007 / \mathrm{s} 00216-016-9599-4$

Thurman, E. M., Ferrer, I., Pozo, O. J., Sancho, J. V., and Hernandez, F. (2007). The even-electron rule in electrospray mass spectra of pesticides. Rapid Commun. Mass Spectrom. 21, 3855-3868. doi: 10.1002/rcm.3271

Trager, W. F. (2007). "Principles of drug metabolism 1: redox reactions, in ADMETox Approaches," in Comprehensive Medicinal Chemistry, 2nd Edn, eds J. B. Taylor and D. J. Triggle (Oxford: Elsevier), 87-132. doi: 10.1016/B0-08-045044-X/00119-X

Tyrkkö, E., Pelander, A., Ketola, R. A., and Ojanperä, I. (2013). In silico and in vitro metabolism studies support identification of designer drugs in human urine by liquid chromatography/quadrupole-time-of-flight mass spectrometry. Anal. Bioanal. Chem. 405, 6697-6709. doi: 10.1007/s00216-013-7137-1

UNODC (2018). World Drug Report 2018, Booklet 3. Available online at: https:// www.unodc.org/pdf/opioids-crisis/WDR18_Booklet_3_DRUG_MARKETS PDF (accessed September 15, 2020).

UNODC (2020). Drug-Related Resolutions and Decisions 2010 to 2019. Available online at: https://www.unodc.org/unodc/en/commissions/CND/Resolutions Decisions/Resolutions-Decisions_2010-2019.html (accessed September 15, 2020).

Uralets, V., Rana, S., Morgan, S., and Ross, W. (2014). Testing for designer stimulants: Metabolic profiles of 16 synthetic cathinones excreted free in human urine. J. Anal. Toxicol. 38, 233-241. doi: 10.1093/jat/bku021

Valente, M. J., Guedes De Pinho, P., De Lourdes Bastos, M., Carvalho, F., and Carvalho, M. (2014). Khat and synthetic cathinones: a review. Arch. Toxicol. 88, 15-45. doi: 10.1007/s00204-013-1163-9

Wagmann, L., Manier, S. K., Eckstein, N., Maurer, H. H., and Meyer, M. R. (2020). Toxicokinetic studies of the four new psychoactive substances 4-chloroethcathinone, N-ethylnorpentylone, N-ethylhexedrone, and 4-fluoro-alpha-pyrrolidinohexiophenone. Forensic Toxicol. 38, 59-69. doi: 10.1007/s11419-019-00487-w

Weinstein, A. M., Rosca, P., Fattore, L., and London, E. D. (2017). Synthetic cathinone and cannabinoid designer drugs pose a major risk for public health. Front. Psychiatry 8:156. doi: 10.3389/fpsyt.2017.00156

Zaami, S., Giorgetti, R., Pichini, S., Pantano, F., Marinelli, E., and Busardò, F. P. (2018). Synthetic cathinones related fatalities: an update. Eur. Rev. Med. Pharmacol. Sci. 22, 268-274.

Zaitsu, K., Katagi, M., Tsuchihashi, H., and Ishii, A. (2014). Recently abused synthetic cathinones, $\alpha$-pyrrolidinophenone derivatives: a review of their pharmacology, acute toxicity, and metabolism. Forensic. Toxicol. 32, 1-8. doi: $10.1007 /$ s11419-013-0218-1

Zuba, D. (2012). Identification of cathinones and other active components of "legal highs" by mass spectrometric methods. Trends Anal. Chem. 32, 15-30. doi: 10.1016/j.trac.2011.09.009

Conflict of Interest: The authors declare that the research was conducted in the absence of any commercial or financial relationships that could be construed as a potential conflict of interest.

Copyright (c) 2021 Lopes, Caldeira, Gaspar and Antunes. This is an open-access article distributed under the terms of the Creative Commons Attribution License (CC $B Y)$. The use, distribution or reproduction in other forums is permitted, provided the original author(s) and the copyright owner(s) are credited and that the original publication in this journal is cited, in accordance with accepted academic practice. No use, distribution or reproduction is permitted which does not comply with these terms. 